\title{
GSR magnitude and judgments of shock as a function of physical intensity of shock intensity
}

\author{
H. D. Kimmel and C. A. Sehultz, Jr. \\ UNIVERSITY OF FLORIDA
}

\begin{abstract}
Observation of GSR and judgments of shock intensity were obtained from nine Ss who received 10 presentations of each of seven shock intensities. Both GSR and judgments were significantly influenced by physical shock intensity. With physical intensity constant (statistically) the correlation between GSR and judgments was significantly positive for two Ss and significantly negative for one $\mathrm{S}$.

\section{Problem}

Recent studies of diminution of the UCR during classical conditioning (Kimble and Ost, 1961; Kimmel and Pennypacker, 1962) suggest the possibility that the inhibition presumably underlying these results is acquired instrumentally; i. e., perhaps the $\mathrm{S}$ learns to reduce the subjective intensity of the UCS by means of an instrumental inhibitory process. To examine this possibility, simultaneous measurements were obtained of GSR magnitude and judgments of shock intensity at several physical intensities of shock.
\end{abstract}

\section{Method}

Nine male undergraduates at the University of Florida volunteered as Ss. Each was run individually.

Ss were told to attend closely to each shock prior to judging its intensity. It was emphasized that judgments were to reflect the way the shock felt to him, not his estimate of its physical properties. S used the following anchors for the extreme positions of the judgment device (see below). Its resting position represented zero shock and its wide open position represented intolerable shock. Intermediate positions were used to reflect variations in perceived intensity of the shock; i. e., the method of magnitude estimation (Stevens, 1956) was used.

Ss were told also that the GSR was being recorded continuously and that unnecessary movement should be avoided.

The palmar GSR was picked up from S's left hand as a DC resistance change, amplified, and recorded on one channel of a dual-channel recorder with a paper speed of $6 \mathrm{in} / \mathrm{min}$.

$\mathrm{S}$ reported his judgments of shock intensity by using his right hand to rotate a lever from its horizontal position. The lever was free to move through $180^{\circ}$. The lever operated a potentiometer in series with a DC source and the second channel of the recorder.

The shock was produced by a constant-current source and delivered to the middle and index fingertips of the right hand. Its duration was 0.1 sec. and its occurrence was marked on the recorder.

Data were collected in an IAC sound-proof room, illuminated by a $100 \mathrm{w}$ lamp. After the equipment was attached to $\mathrm{S}$ and the judgment device's operation demonstrated, the doors were closed and the instructions delivered via an intercom. S then received some sample shocks including the least and most intense to be used. Then actual data-collection began. This consisted of 10 presentations of each of seven intensities of shock, $0.5,1.0,1.5,2.0,2.5,3.0$, and 3.5 mamps, in a random order restricted so that each occurred twice in a block of 14 trials. Trials were separated by 15-45 sec. After each shock was presented, S reported his judgment of its intensity by rotating the lever and then returned it to its resting position. At the end of the 70 trials, S was asked to move the lever several times without shock. Only negligible GSR activity was observed during these movements.

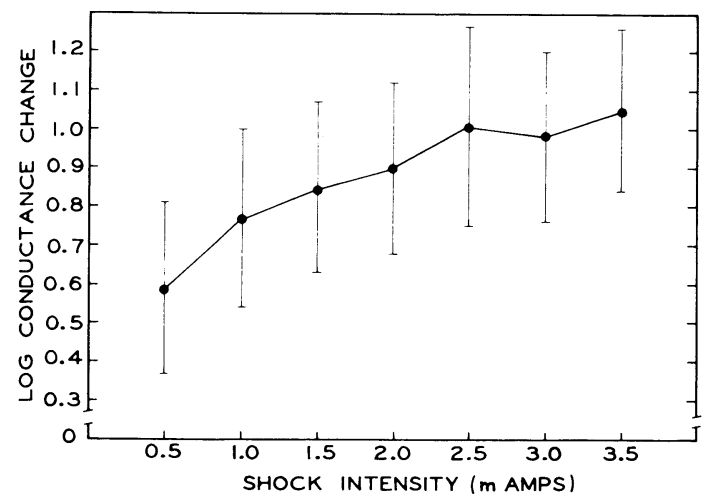

Fig. 1. Average GSR $( \pm 1 \mathrm{SD})$ at 7 shock intensities. 


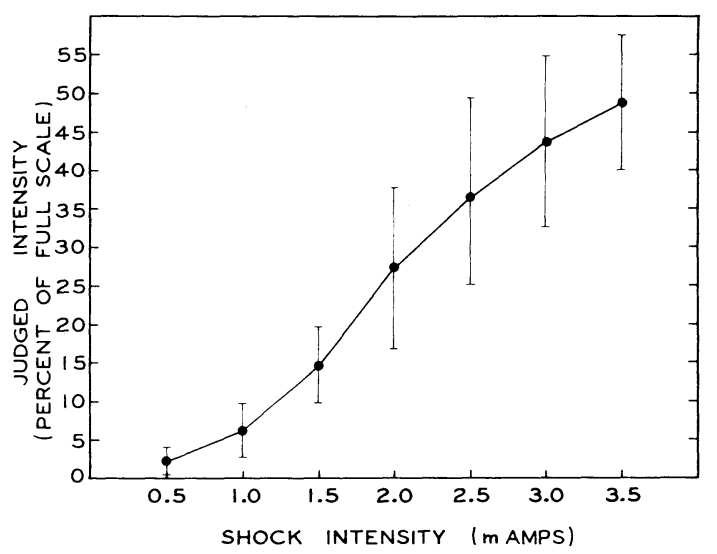

Fig. 2. Average judged intensity $( \pm 1$ SD) at 7 intensities.

\section{Results}

The GSR occurring within 4 sec. of each shock was transformed into units of log conductance change. These values were averaged for each shock intensity for each S. Figure 1 shows the average GSR across Ss for the seven intensities of shock. Also shown in the figure are the SDs $( \pm 1)$ for each shock value. The negatively accelerated upward trend in the GSR means was highly significant, $F(6,48)=21.81$. The correlation (intraclass) between shock intensity and the GSR was 0.70 (the proportion of intra-individual variance associated with shock intensity).

Judgments of intensity of each shock were measured in units of per cent of maximum possible movement of the judgment device, a linear function of actual responses. These values were averaged for each shock intensity for each $\mathrm{S}$. Figure 2 shows the average judgment across Ss along with \pm 1 SD for the seven shock intensities. The s-shaped upward trend in the judgment means was highly significant, $\mathrm{F}(6,48)=90.49$. The correlation (intraclass) between shock intensity and judgments of intensity was 0.91 .

The correlation between the GSR and judgments of intensity (based upon deviations from shock-group means to overcome the fact that both variables correlated significantly with shock) was obtained separately for each S. For two of the nine Ss these correlations were significantly greater than zero $(r=0.76$ and 0.33 , both $\mathrm{Ps}<.01)$, while for one $\mathrm{S}$ the correlation was significantly below zero $(\mathrm{r}=-0.25, \mathrm{P}<.05)$. For the remaining six Ss these correlations were not significantly different from zero.

\section{Discussion}

The results of this study indicate that both the GSR and judgments of shock intensity vary significantly in relation to variations in actual physical intensity of shock. As the physical intensity of shock is increased the GSR it produces increases and the $S$ reports an increase in felt-intensity. However, when physical intensity is held constant by partialling its effect out, only two Ss showed the expected positive relationship between variations in GSR and judgments. It is exactly in the case of constant physical shock (i. e., in classical GSR conditioning) that we have suspected that reduced GSRs might reflect reduced impressions of shock intensity.

There appear to be only two "ways out", for the instrumental-inhibition position. The first is that there may actually be a change in the "physical" properties of the repeatedly delivered, constant UCS in classical conditioning (by means of receptor and/or afferent neural changes). Thus, the GSR and felt-intensity would covary positively during conditioning. The second possibility is that only a small percentage of Ss show the assumed relationship. In this connection it should be noted that Kimble and Ost (1961) identified a small group of Ss who showed considerably more UCR-diminution than the rest of their sample.

\section{References}

KIMBLE, G. A. and OST, J. W. P. A conditioned inhibitory process in eyelid conditioning. J. exp. Psychol., $1961,61,150-156$.

KIMMEL, H. D. and PENNYPACKER, H. S. Conditioned diminution of the unconditioned response as a function of the number of reinforcements.J.exp. Psychol., 1962, 64, 20-23.

STEVENS, S. S. The direct estimation of sensory magnitudes - loudness. Amer. J. Psychol., 1956, 69, $1-25$.

\section{Acknowledgment}

Done under Public Health Grant MH - 06060 - 02. 